\title{
Experimental Study of Heat Transfer between Dissociated Air Flow and a Flat Plate at Angle of Attack in RF-Plasmatron
}

\author{
A.V. Chaplygin, A.N. Gordeev \\ Ishlinsky Institute for Problems in Mechanics of the Russian Academy of Sciences, \\ Moscow, 119526, Russia \\ alchap187@gmail.com
}

\begin{abstract}
The heat transfer from subsonic jets of dissociated air flowing from a slit nozzle to the surface of a flat plate at angle of attack was experimentally studied by the RF-plasmatron IPG-4. The influence of pressure in the chamber of plasmatron on the range of the air plasma jet was studied. The influence of generator power on distribution of heat flux on the surface of copper plate at the angle of attack at pressures in the chamber of 50 and $100 \mathrm{hPa}$ was studied. The heat fluxes for the low-catalytic surface of the heat-shielding tile of the «Buran» orbital vehicle were determined depending on the generator power, pressure in the chamber and angle of attack. A comparison of the heat exchange parameters for the copper surface and the low catalytic surface of the heat-shielding tile of the «Buran» orbital vehicle for the same flow regime was carried out.
\end{abstract}

Keywords: RF-plasmatron, slit nozzle, dissociated air, heat transfer, plate at angle of attack.

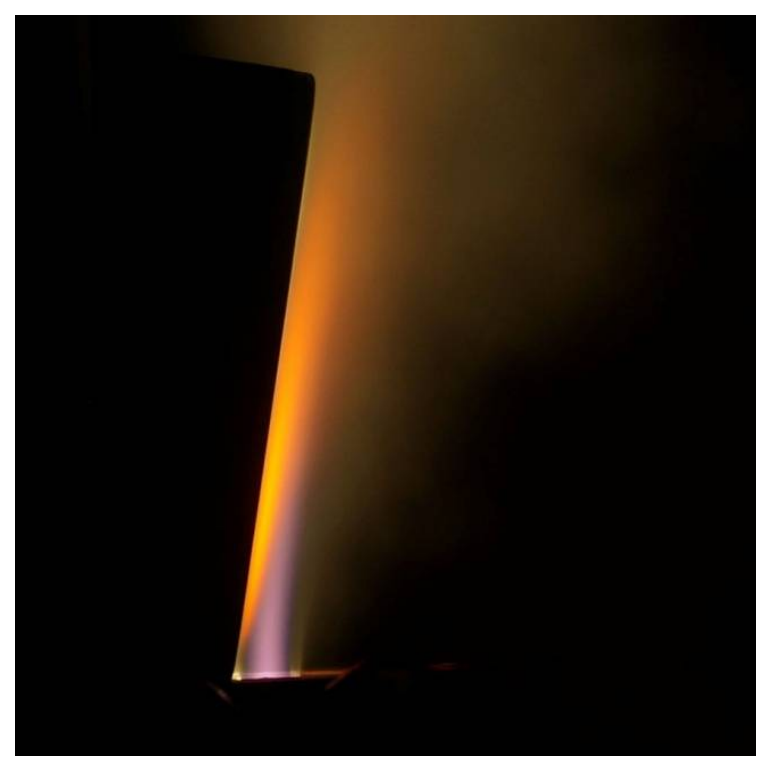

Heat-shielding tile of the «Buran» orbital vehicle at angle of attack in the dissociated air flow 


\title{
Экспериментальное исследование теплообмена диссоциированного потока воздуха с плоской пластиной под углом атаки в ВЧ-плазмотроне
}

\author{
А.Н. Гордеев, А.В. Чаплыгин \\ Федеральное государственное бюджетное учреждение науки \\ Институт проблем механики им. А.Ю. Иилинского РАН, \\ Россия, Москва, 119526, пр-т Вернадского, д.101, корп.1 \\ alchap187@gmail.com
}

\begin{abstract}
Аннотация
В ВЧ-плазмотроне ВГУ-4 был экспериментально исследован теплообмен дозвуковых струй диссоциированного воздуха, истекающих из щелевого сопла, с поверхностью плоской пластины под углом атаки. Исследовано влияние давления в барокамере установки на дальнобойность струи воздушной плазмы. Исследовано влияние мощности генератора на распределение теплового потока по поверхности медной пластины под углом атаки при давлении в барокамере 50 и 100 гПа. Определены тепловые потоки для низкокаталитической поверхности теплозащитной плитки орбитального корабля «Буран» в зависимости от мощности генератора, давления в барокамере и угла атаки. Проведено сравнение параметров теплообмена для медной поверхности и низкокаталитической поверхности теплозащитной плитки орбитального корабля «Буран» для одинакового режима обтекания.
\end{abstract}

Ключевые слова: ВЧ-плазмотрон, щелевое сопло, диссоциированный воздух, теплообмен, пластина под углом атаки.

\section{1. Введение}

Испытания теплозащитных материалов для высокоскоростных летательных аппаратов в установках аэродинамического нагрева традиционно проводят на осесимметричных образцах (цилиндр с плоским торцом или сферическим притуплением, «Евромодель» и др.) [1-5].

Эти формы обладают рядом преимуществ:

- простота расчетного моделирования эксперимента;

- $\quad$ удобство экспериментального определения характеристик потока;

- $\quad$ возможность обеспечить однородное температурное поле в окрестности передней критической точки образца;

- $\quad$ возможность поставить в соответствие эксперименту реальные условия обтекания [6]. пластин.

Но аэрокосмической промышленностью востребованы и испытания образцов в форме

В случае плиточной теплозащиты многоразовых космических аппаратов («Space Shuttle», «Буран», «X-37» и др.) такая форма дает возможность испытывать близкие к натурным (или натурные) элементы конструкции.

Образец в форме пластины позволяет реализовать в рамках одного испытания градиентное поле температур на поверхности, что в совокупности с современными методами оптической пирометрии существенно расширяет объем получаемых в ходе эксперимента результатов. В одном эксперименте может быть получен массив информации о состоянии 
исследуемого материала в зависимости от температуры конкретного участка. Для образцов в форме тел вращения сбор подобных данных потребовал бы серии экспериментов (по отдельному эксперименту для каждого значения температуры в области передней критической точки).

Принципиальной особенностью испытания пластины является возможность, варьируя угол атаки, снизить уровень теплового потока на поверхности материала до значений недоступных в режиме лобового натекания, что существенно расширяет рабочий диапазон установки.

Исследования образцов-пластин в потоках диссоциированных газов проводились во многих лабораториях, специализирующихся на испытаниях высокотемпературных материалов.

В ФГУП ЦНИИМаш при испытаниях плоских образцов под углом атаки в установке У13-ВЧП используется щелевое сопло с выходным сечением $50 \times 270$ мм [7]. Фото процесса испытания представлено на рис. 1.

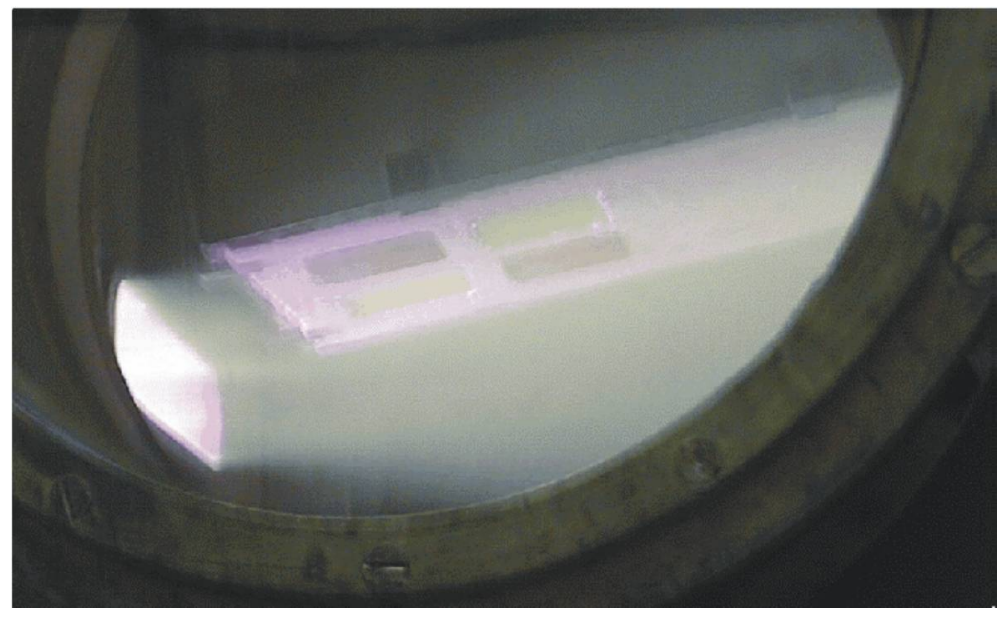

Рис. 1. Щелевое сопло в установке У13-ВЧП ФГУП ЦНИИМаш [7]

В Институте фон Кармана (Von Karman Institute for Fluid Dynamics, VKI) при отработке на индукционном плазмотроне мощностью 1.2 МВт теплозащитных материалов для аппаратов EXPERT и IXV испытывались образцы в форме прямоугольных пластин [8], образцы устанавливались в разработанную для этих целей водоохлаждаемую модель, которая вводилась в поток диссоциированнного воздуха, истекающий из цилиндрического разрядного канала диаметром 160 мм.

В Исследовательском центре Эймса (Ames Research Center, ARC) применяется специализированная установка для исследования плоских образцов (панелей) - Panel Test Facility (PTF) мощностью 20 МВт $[9,10]$. Установка позволяет проводить испытания плоских образцов размером $360 \times 360$ мм при углах атаки от $-4^{\circ}$ до $15^{\circ}$.

Один из ключевых недостатков образцов в форме пластин при исследовании высокотемпературных материалов в высокочастотных индукционных плазмотронах - сложность численного моделирования трехмерной задачи обтекания подобных объектов высокоэнтальпийным потоком, поскольку течение имеет сложный пространственный характер. В этих условиях особое внимание должно быть уделено экспериментальным исследованиям режимов обтекания и теплообмена.

В представленной работе исследуется теплообмен истекающего из щелевого сопла дозвукового потока диссоциированного воздуха индукционного плазмотрона ВГУ-4 (ИПМех PАН) с плоскими пластинами, обтекаемыми под различными углами атаки. 


\section{2. Экспериментальная установка}

Эксперименты проводились в 100-киловаттном высокочастотном индукционном плазмотроне ВГУ-4. Принципиальная схема установки ВГУ-4 показана на рис. 2, а ее основные характеристики представлены в табл. 1. Подробное описание плазмотрона ВГУ-4 приведено в [11].

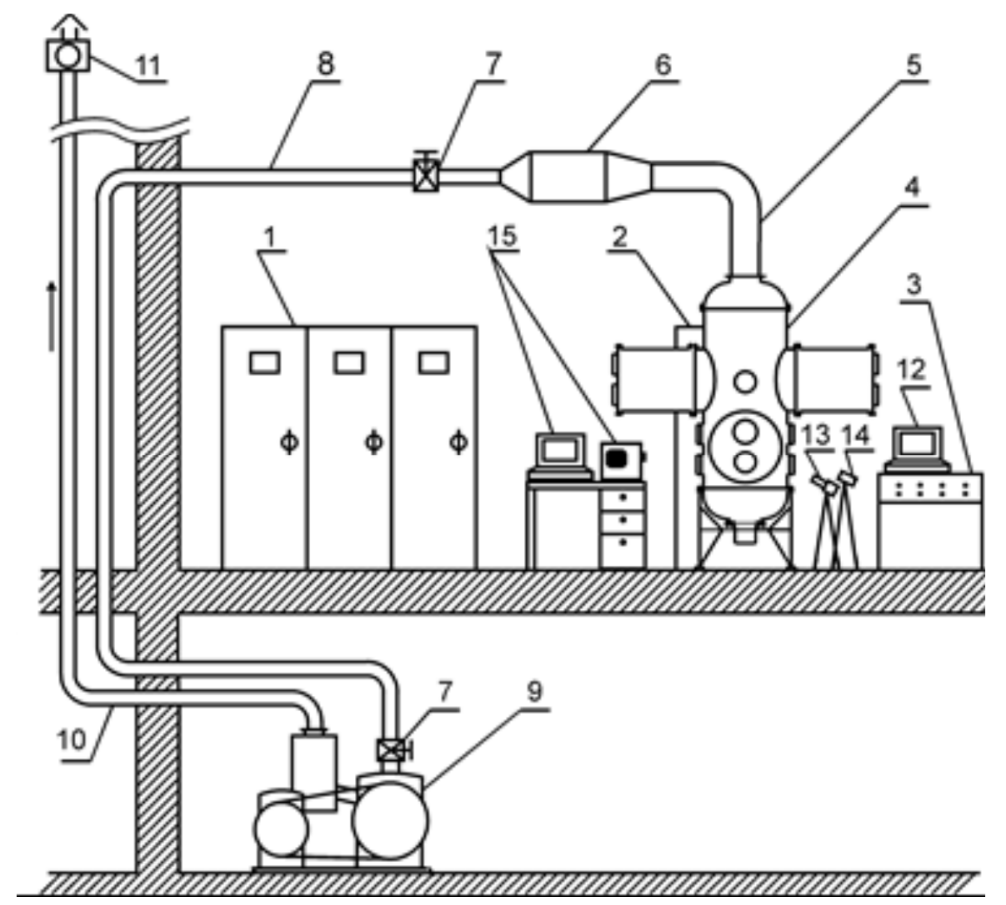

Рис. 2. Принципиальная схема высокочастотного индукционного плазмотрона ВГУ-4: 1 - ВЧ-генератор; 2 - блок согласования плазменной нагрузки с ВЧ-генератором, 3 - пульт управления, 4 - испытательная камера, 5 - водоохлаждаемый вакуумный трубопровод, 6 - теплообменник «плазма-вода», 7 - вакуумные вентили, 8 - вакуумный трубопровод, 9 - вакуумный насос, 10 - вытяжной трубопровод, 11 - вытяжной вентилятор, 12 - компьютер системы сбора и регистрации данных, 13 - термовизор, 14 - пирометр, 15 - спектрометр

Таблица 1

Основные характеристики установки ВГУ-4

\begin{tabular}{|l|c|}
\hline Мощность анодного питания, кВт & $12 \div 72\left(85^{*}\right)$ \\
\hline Частота, МГц & 1.76 \\
\hline Диаметр разрядного канала, мм & 80 \\
\hline Расход воздуха, г/с & $2 \div 6$ \\
\hline Режим течения потока плазмы & $\begin{array}{c}\text { Дозвуковой и } \\
\text { сверхзвуковой }\end{array}$ \\
\hline Давление в испытательной камере, гПа & $6 \div 1000$ \\
\hline
\end{tabular}

*кратковременно 
При исследованиях плоских образцов под углом атаки в установке ВГУ-4 используется щелевое водоохлаждаемое сопло с размерами выходного сечения 80x15 мм. Схема эксперимента с использованием теплозащитной плитки орбитального корабля «Буран» показана на рис. 3.

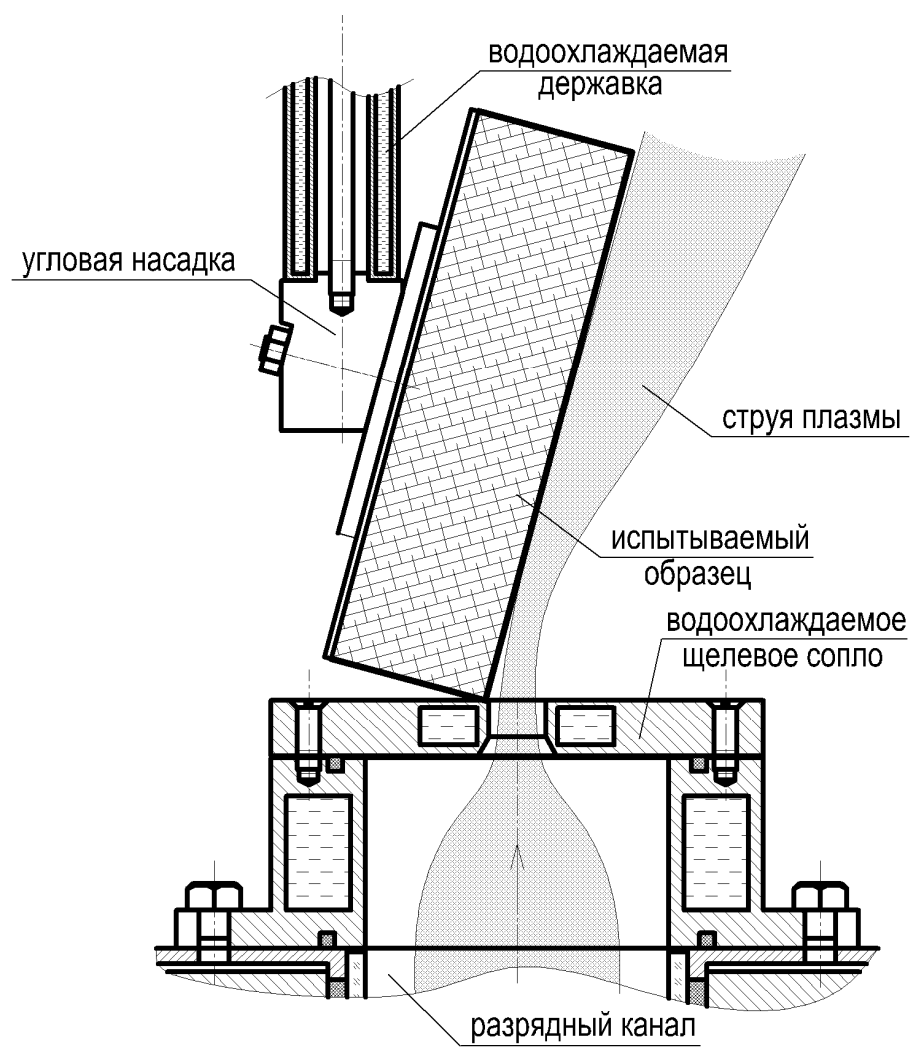

Рис. 3. Схема эксперимента с использованием теплозащитной плитки орбитального корабля «Буран»

\section{3. Режимы работы плазмотрона}

Было исследовано влияние давления в барокамере установки ВГУ-4 на картину истечения воздушной плазмы из щелевого сопла с выходным сечением $80 \times 15$ мм при постоянном значении расхода воздуха $(2.4$ г/с) и мощности анодного питания (45 кВт). Внешний вид струи при давлениях в барокамере 50, 100, 400 и 700 гПа представлен на рис. 4, из которого видно, что с ростом давления дальнобойность струи уменьшается.

Таким образом, для экспериментов с использованием щелевого сопла с выходным сечением $80 \times 15$ мм в установке ВГУ-4 предпочтительны давления, не превышающие 100 гПа. Для дальнейшего определения параметров теплообмена были выбраны опорные значения давления в барокамере 50 и 100 гПа. При этих давлениях реализуется максимальная дальнобойность струи.

Интервал мощностей анодного питания, при которых могут проводиться эксперименты с пластиной, для указанных давлений составляет $16 \div 72$ кВт. Нижняя граница по мощности определяется областью существования разряда для случая истечения из щелевого сопла [12], верхняя - предельной допустимой мощностью анодного питания установки ВГУ-4 при работе на стационарном режиме. 


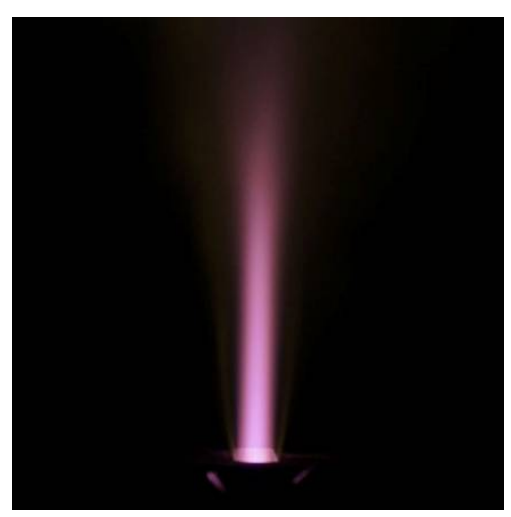

$a$

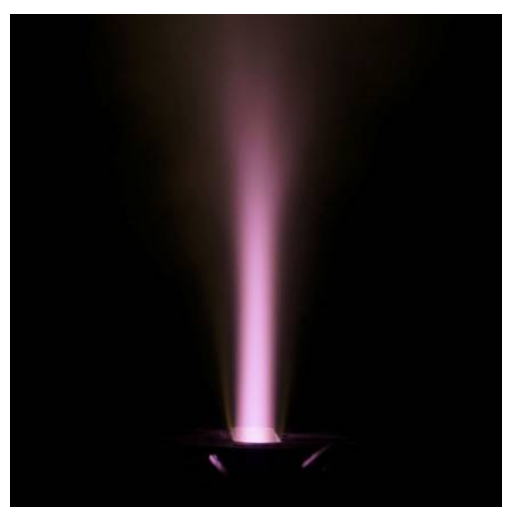

B

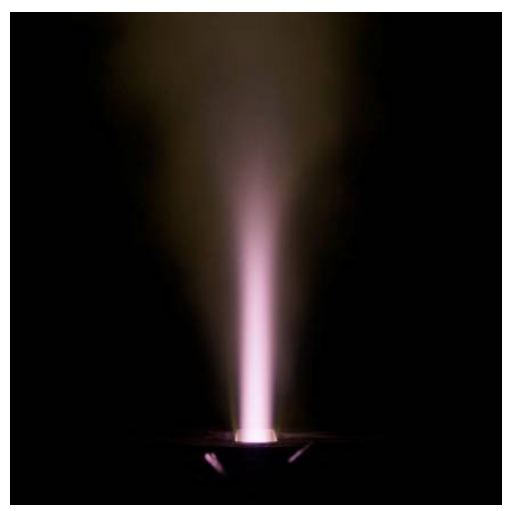

$\partial$

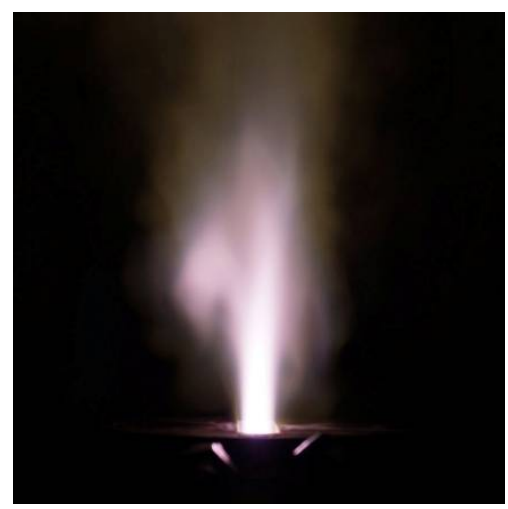

ЖC
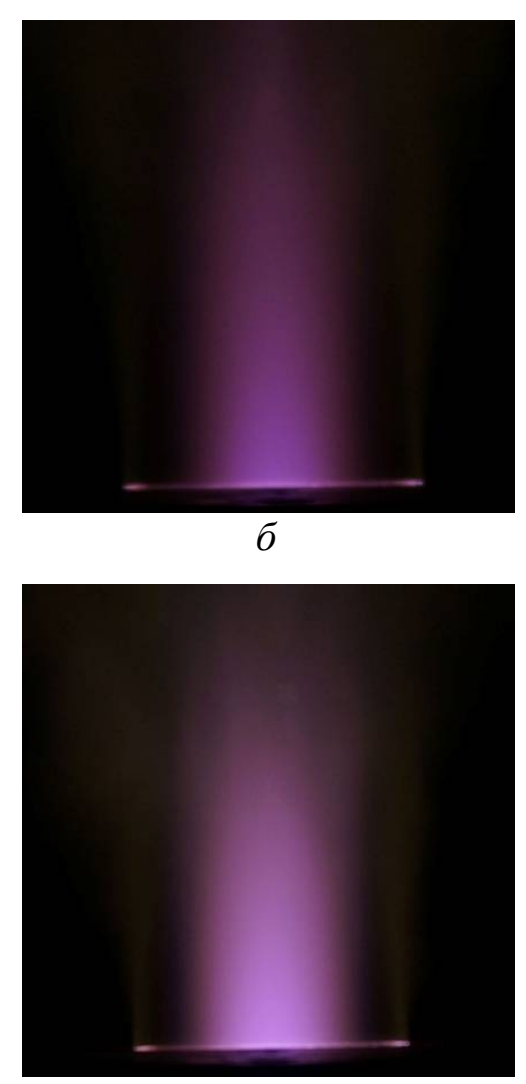

2

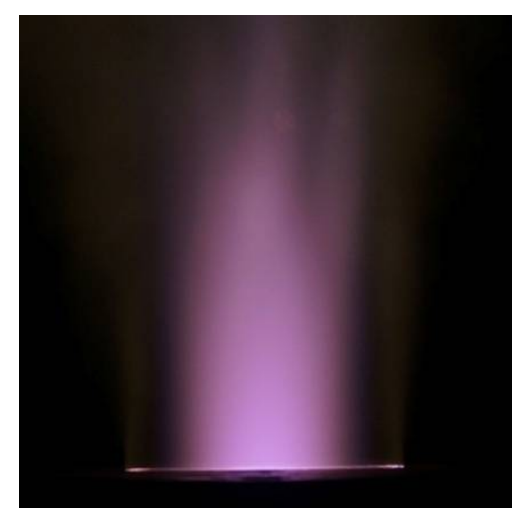

e

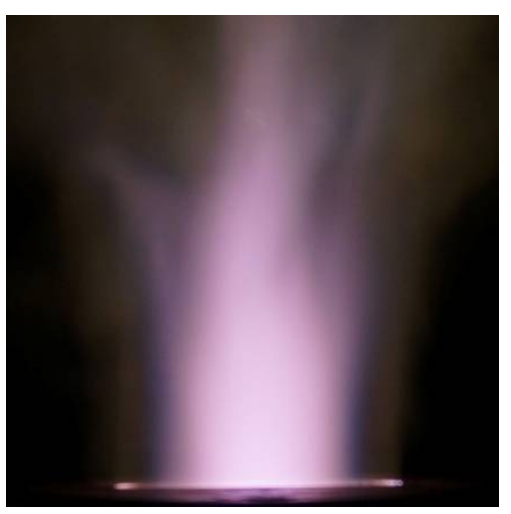

3

Рис. 4. Вид струи воздушной плазмы, истекающей из щелевого сопла с выходным сечением $80 \times 15$ мм при постоянной мощности анодного питания $\mathrm{N}=45$ кВт и различных давлениях в камере установки $-a, \sigma-p=50$ гПа; $в, 2-p=100$ гПа; $\partial, e-p=400$ гПа; ж, з- $p=700$ гПа 


\section{4. Определение тепловых потоков к высококаталитической медной поверхности пластины}

Для определения тепловых потоков, реализуемых в условиях эксперимента, применяются калориметрические датчики различных конструкций.

В Институте фон Кармана разработана модель в форме пластины со скругленными кромками [13]. На боковой поверхности модели, в прямоугольном гнезде, устанавливаются восемь медных датчиков теплового потока, работающих по принципу стационарного водоохлаждаемого калориметра, в этом же гнезде может быть размещен исследуемый образец материала (рис. 5). Эта модель допускает проведение экспериментов только под нулевым углом атаки

Перепад температуры воды между входом и выходом каждого датчика измеряется термопарами. При этом тепловой поток определяется по формуле

$$
q_{c}=\frac{\dot{m}_{\mathrm{H}_{2} \mathrm{O}} C_{p}}{d} \frac{\partial T}{\partial x}
$$

где $d$-ширина датчика; $C_{p}$-теплоемкость воды; $\dot{m}_{\mathrm{H}_{2} \mathrm{O}}-$ массовый расход воды; $\partial T / \partial x$ - измеряемый перепад температур.

Датчики соединены в контуре охлаждения последовательно, что накладывает ограничения на максимальный уровень тепловых потоков, которые могут измеряться, в связи с риском закипания воды в калориметре. В [13] приводятся данные измерений калориметром тепловых потоков вплоть до $42 \mathrm{~B}$ т/ $\mathrm{cm}^{2}$.

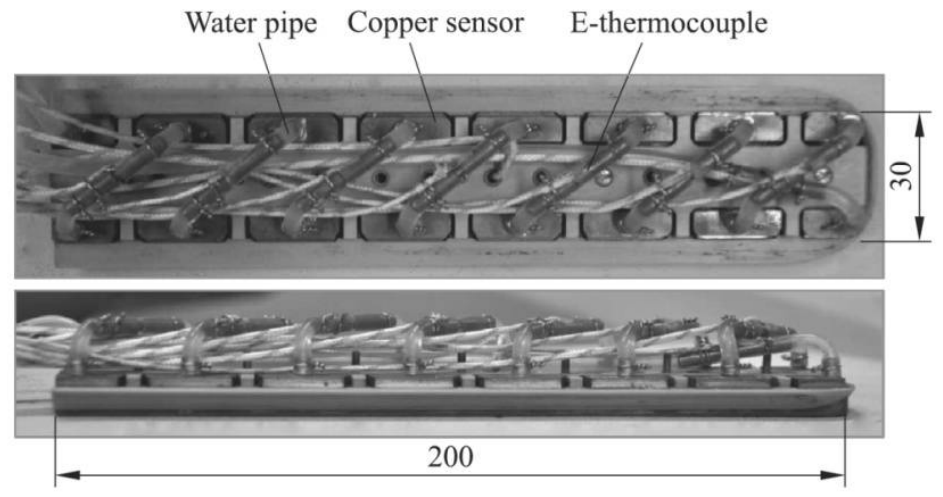

$a$

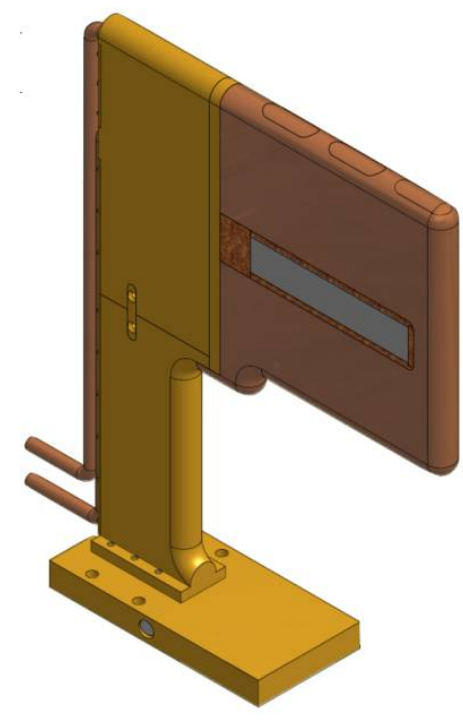

6

Рис. 5. Водоохлаждаемый плоский калориметр (a) разработки Института фон Кармана и способ его установки в модели (б) [8], [13]

В Исследовательском центре Эймса для определения тепловых потоков применяется калибровочная пластина (рис. 6) с установленными в ней двенадцатью водоохлаждаемыми датчиками теплового потока (калориметрами Гардона) [14]. Максимальный тепловой поток, который может быть измерен этими датчиками составляет $300 \mathrm{BT} / \mathrm{cm}^{2}$.

Для измерения тепловых потоков к поверхности пластины под углом атаки в установке ВГУ-4 использовалась медная неохлаждаемая модель с интегрированными в нее четырьмя нестационарными калориметрическими датчиками тепловых потоков (рис. 7). 


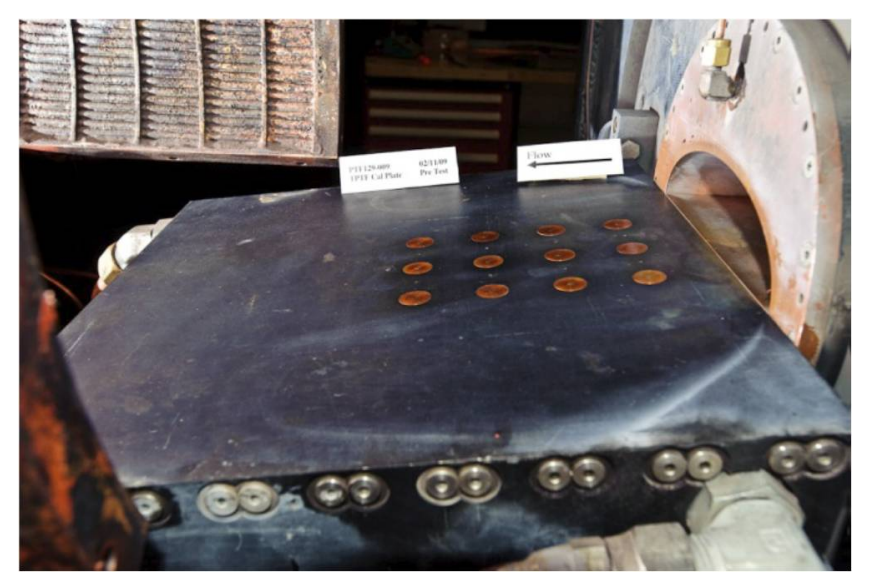

Рис. 6. Калибровочная пластина с датчиками тепловых потоков в установке РТF Исследовательского центра Эймса [14]
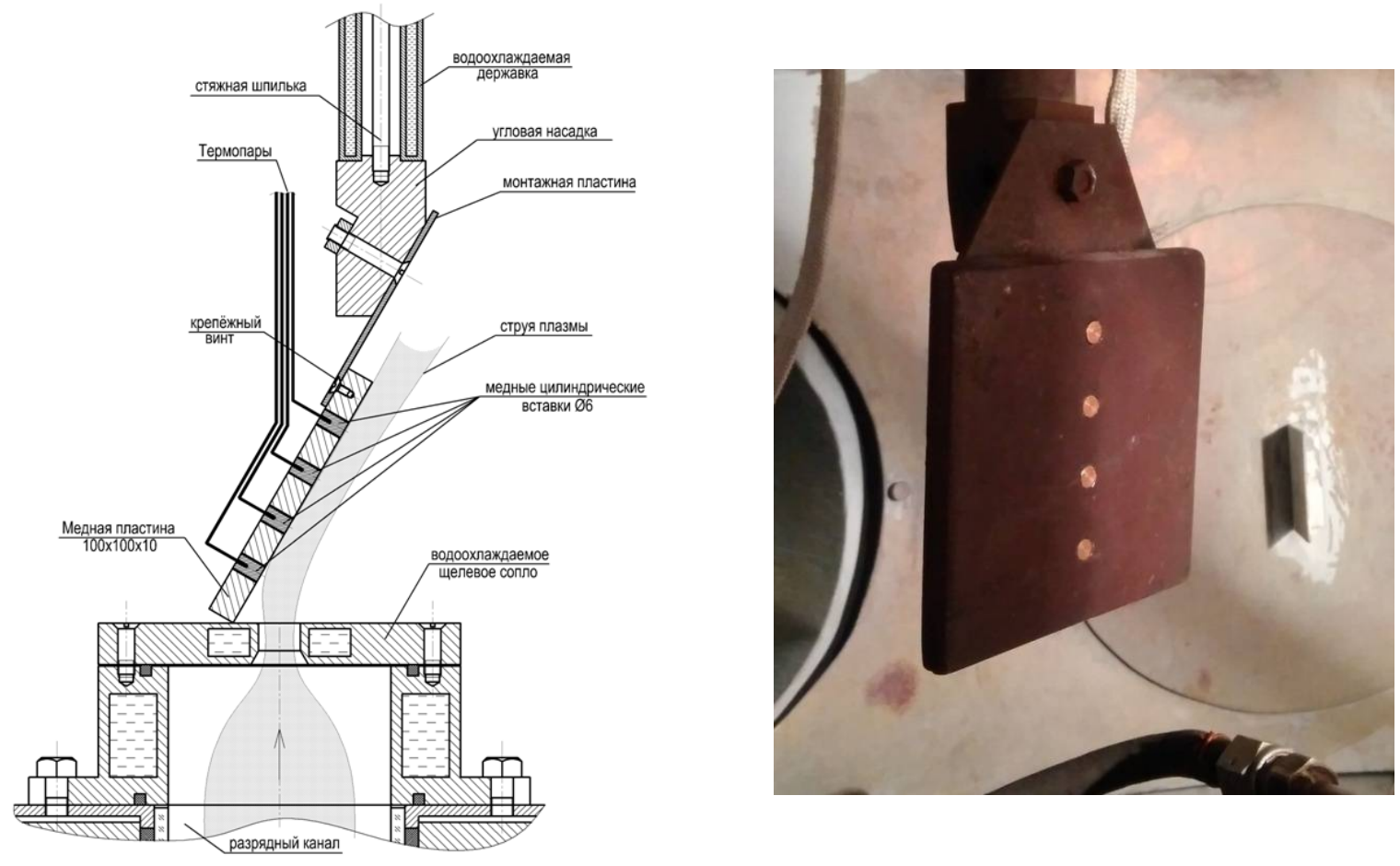

Рис. 7. Модель-пластина для измерения тепловых потоков в установке ВГУ-4

Каждый датчик представляет собой цилиндр из бескислородной меди диаметром $d=6$ мм, массой 2.51 г с термопарой на тыльной стороне. Датчики располагаются вдоль вертикальной оси симметрии пластины с размерами $100 \times 100 \times 10$ мм на расстоянии 20, 40, 60 и 80 мм от нижнего края лицевой поверхности. Картина обтекания медной пластины потоком представлена на рис. 8 .

Методика измерения тепловых потоков нестационарными калориметрическими датчиками подробно изложена в [15]. В процессе эксперимента регистрируется изменение температуры на тыльной стороне датчика, тепловой поток определяется из соотношения

$$
q_{c}=\frac{M \cdot C_{p}}{A} \frac{\Delta T}{\Delta t}
$$

где $M$ - масса датчика; $C_{p}$ - теплоемкость материала датчика; $A$ - площадь нагреваемой поверхности датчика; $\Delta T / \Delta t$ - регистрируемая скорость роста температуры. 


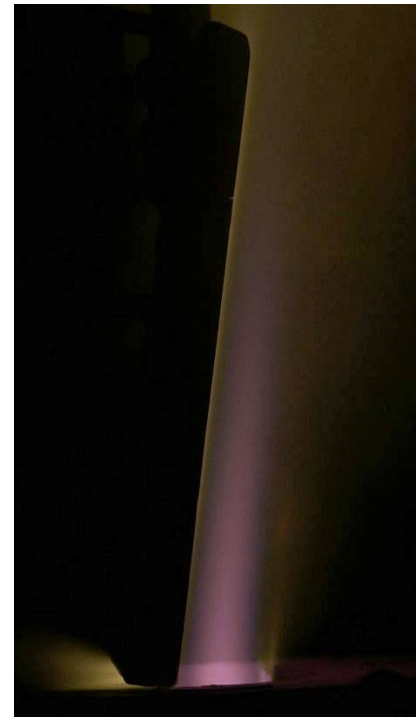

$a$

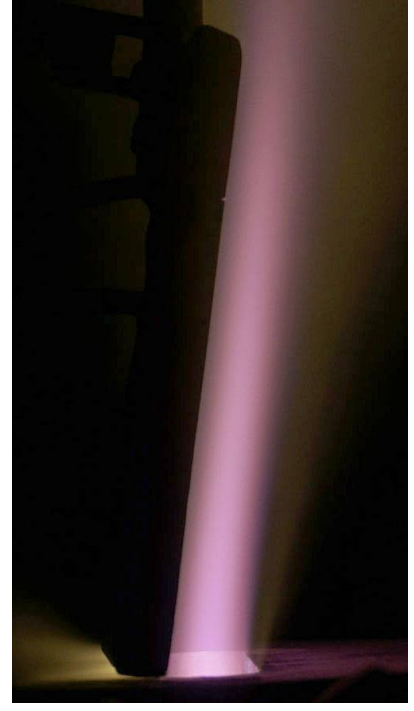

6

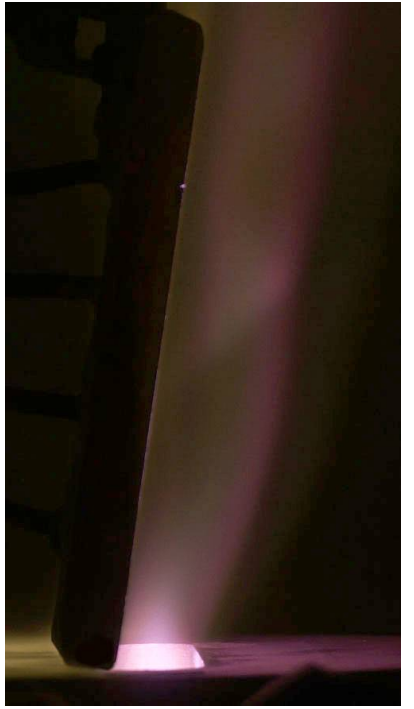

B

Рис. 8. Модель-пластина при различных режимах обтекания: $a-p=50$ гПа, $N=20$ кВт; $\sigma-p=50$ гПа, $N=40$ кВт; $в-p=9.5$ гПа, $N=40$ кВт (сверхзвуковой поток)

Типичные графики изменения температуры датчиков в ходе эксперимента показаны на рис. 9. Для определения скорости роста температуры $\Delta T / \Delta t$ выбирают линейный участок кривой, соответствующий установившемуся режиму нагрева.

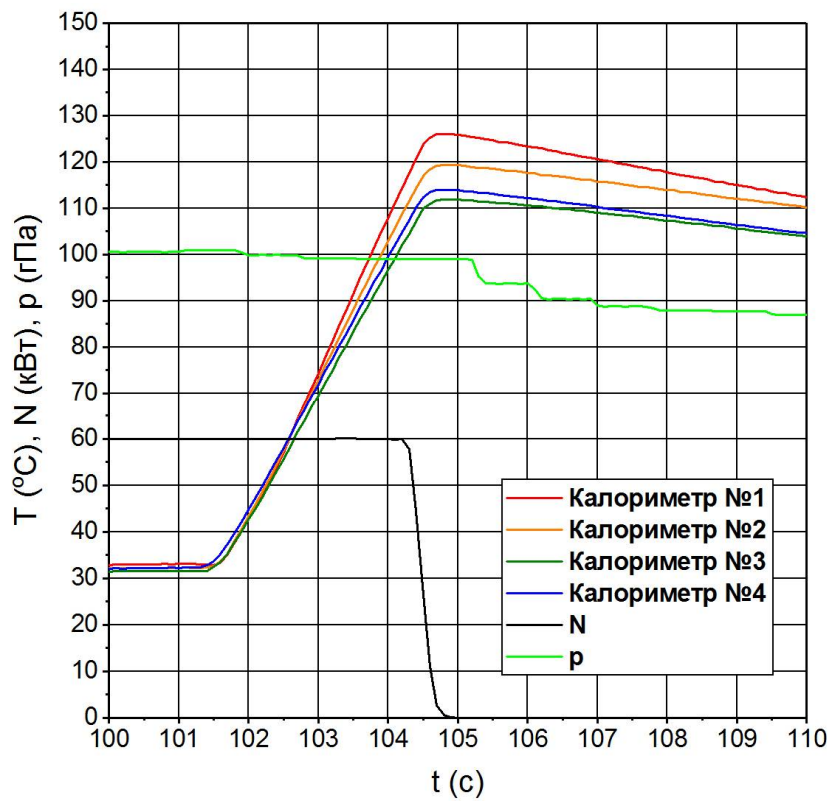

Рис. 9. Типичные графики изменения температуры тыльной поверхности датчиков тепловых потоков в процессе эксперимента

Выбранная методика измерения тепловых потоков широко распространена. Аналогичные датчики применялись в Исследовательском центре Эймса [16], Университете штата Вермонт (The University of Vermont) [17] и в ФГУП ЦНИИМаш [18].

Тепловые потоки определялись при давлении в барокамере установки 50 и 100 гПа для диапазона мощностей анодного питания от 20 до 70 кВт, модель-пластина устанавливалась под углами $0^{\circ}, 5^{\circ}, 15^{\circ}$ и $30^{\circ}$ и вводилась в струю таким образом, что линия нижней кромки пластины совмещалась с краем выходного сечения щелевого сопла, зазор отсутствовал. Результаты измерения тепловых потоков приведены на рис. 10-11. 


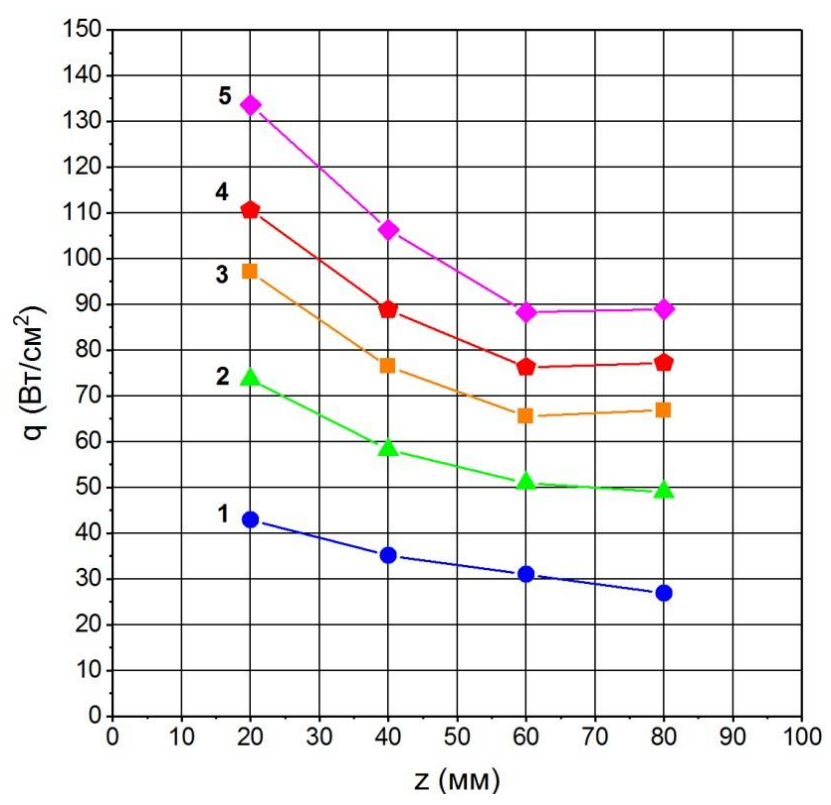

Рис. 10. Изменение теплового потока вдоль оси симметрии медной пластины для различных значений мощности плазмотрона при давлении в барокамере 50 гПа и угле атаки $5^{\circ} . \mathrm{z}$ (мм) - координата, отсчитываемая по поверхности пластины от среза сопла, $\mathrm{q}\left(\mathrm{BT} / \mathrm{cm}^{2}\right)$ - плотность теплового потока. Мощность плазмотрона по анодному питанию $\mathrm{N}$ : 1 (синий) - 20 кВт, 2 (зеленый) - 30 кВт, 3 (оранжевый) - 40 кВт, 4 (красный) - 50 кВт, 5 (розовый) -60 кВт

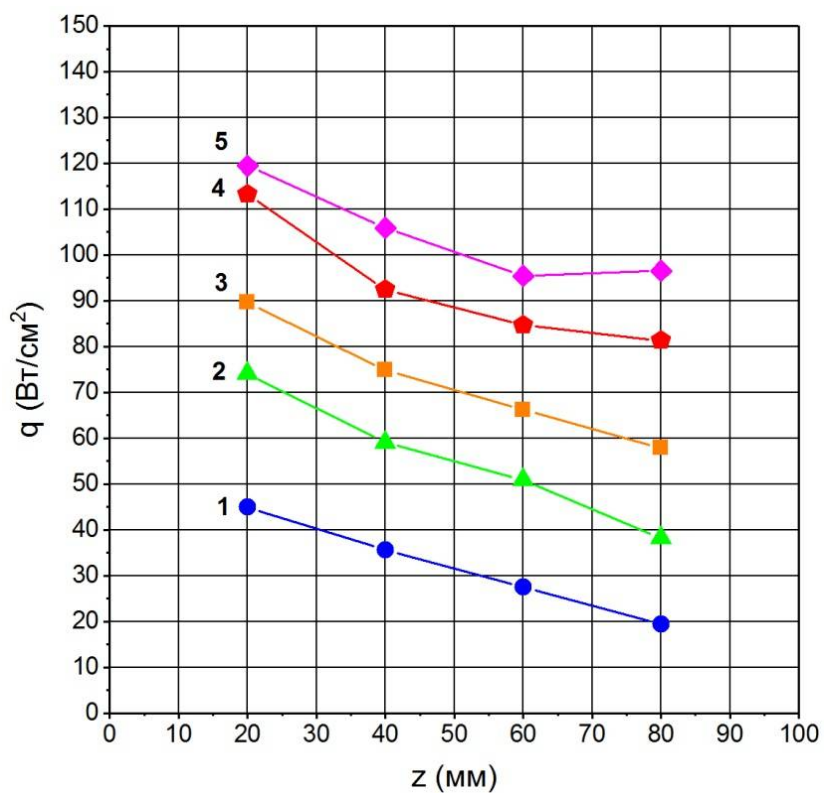

Рис. 11. Изменение теплового потока вдоль оси симметрии медной пластины для различных значений мощности плазмотрона при давлении в барокамере 100 гПа и угле атаки $5^{\circ} . \mathrm{z}($ мм) - координата, отсчитываемая по поверхности пластины от среза сопла, $\mathrm{q}\left(\mathrm{B} / \mathrm{cm}^{2}\right)$ - плотность теплового потока. Мощность плазмотрона по анодному питанию $\mathrm{N}$ : 1 (синий) - 20 кВт, 2 (зеленый) - 30 кВт, 3 (оранжевый) - 40 кВт, 4 (красный) - 50 кВт, 5 (розовый) -60 кВт

При сравнении рис. 10 и рис. 11 можно видеть, что при давлении в барокамере 100 гПа тепловой поток по мере удаления от среза сопла падает быстрее, чем при давлении 50 гПа, что согласуется с фотографиями на рис. 8 , из которых видно снижение дальнобойности струи по мере роста давления. С ростом подводимой мощности тепловой поток на участке, распо- 
ложенном в $60 \div 80$ мм от нижнего края пластины, практически перестает зависеть от координаты, причем в точке, удаленной на расстояние 80 мм, он даже превышает значение на расстоянии 60 мм. Чтобы подтвердить системность данного явления, в поток вводилась пластина из древесно-слоистой плиты тех же размеров, что и медная пластина, используемая при измерении тепловых потоков. Унос материала на оси симметрии плиты находился в качественном соответствии с полученными распределениями тепловых потоков. Отмеченное явление, вероятно, связано с отрывом потока у задней кромки пластины.

С целью оценки повторяемости результатов измерения при давлении 50 гПа проводились сериями по пять пусков для каждого значения мощности. Зависимости 1-5 на рис. 10 построены на основе осреднения полученных величин тепловых потоков. Отклонение значений в отдельных экспериментах от среднего не превышало $2.5 \%$. Между сериями экспериментов модель и сопло не демонтировались из установки.

Для мощности 30 кВт была проведена дополнительная серия экспериментов, в которой сопло и пластина заново монтировались в установке. В точках, удаленных на расстояние 40 и 60 мм от нижнего края пластины, полученные величины находятся в определенном для предыдущей серии пусков коридоре значений. В точках, расположенных на расстоянии 20 и 80 мм от нижнего края пластины, тепловой поток отличался от среднего для основной серии пусков на 8.4 и $3.6 \%$ соответственно.

Сравнительно большой разброс значений в точке, удаленной на 20 мм от нижнего края пластины, можно объяснить тем, что в этой области происходит поворот истекающей из щелевого сопла струи плазмы, что приводит к уменьшению толщины пограничного слоя. Тепловой поток в этом случае оказывается чувствителен даже к незначительному изменению положения пластины относительно выходного сечения сопла.

В точке, удаленной на 80 мм от нижнего края пластины, результаты измерений могут быть подвержены влиянию явлений отрыва потока на задней кромке пластины и/или начала распада струи.

При давлении 100 гПа повторные измерения тепловых потоков не проводились.

При давлении в камере установки 50 гПа была исследована зависимость наблюдаемых тепловых потоков от угла атаки. Результаты измерений для датчика на расстоянии 40 мм от нижнего края пластины приведены на рис. 12.

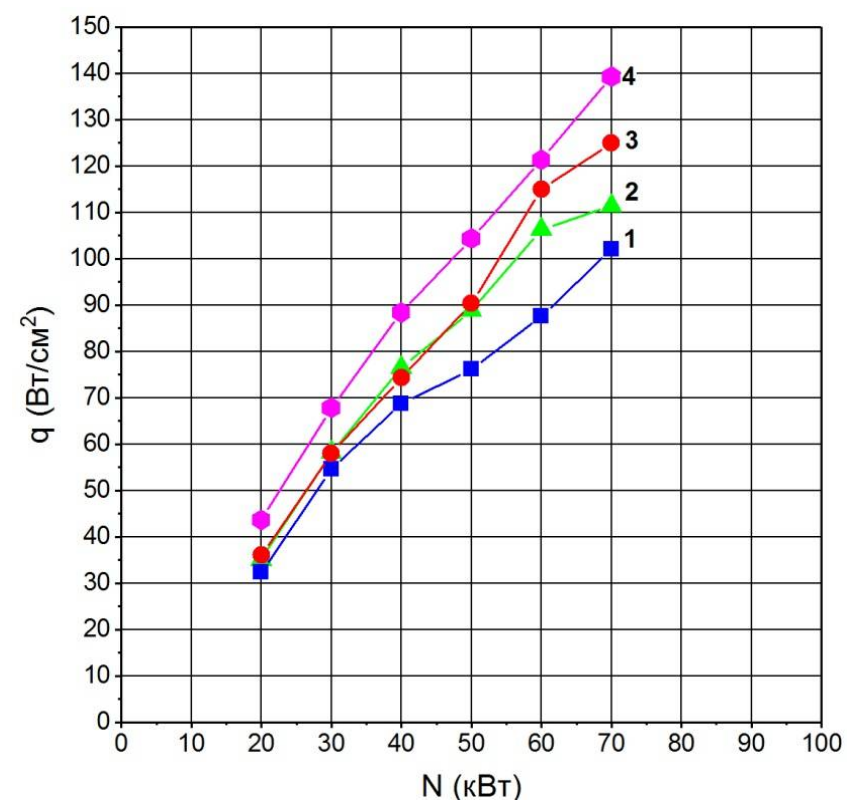

Рис. 12. Изменение теплового потока в точке на расстоянии 40 мм от нижнего края медной пластины для различных значений мощности плазмотрона при давлении в барокамере 50 гПа и угле атаки: 1 (синий) $-0^{\circ} ; 2$ (зеленый) $-5^{\circ} ; 3$ (красный) $-15^{\circ}$; 4 (розовый $)-30^{\circ}$ 
При малых значениях мощности (от 20 до 40 кВт) изменение угла атаки слабо влияет на величину теплового потока. С увеличением мощности влияние угла атаки становится более выраженным. В целом же имеет место рост теплового потока с увеличением угла атаки.

Стабильным в части повторяемости режимов обтекания и однородности картины распределения тепловых потоков является участок поверхности на расстоянии $40 \div 60$ мм от нижнего края пластины. При давлении в камере установки 50 гПа на этом участке регистрировались тепловые потоки от $30 \mathrm{Bт} / \mathrm{cm}^{2}$ (при мощности анодного питания 20 кВт и угле атаки $0^{\circ}$ ) до $140 \mathrm{BT} / \mathrm{cm}^{2}$ (при мощности анодного питания 70 кВт и угле атаки $30^{\circ}$ ).

Максимальное зарегистрированное значение теплового потока для исследованных при давлении 50 гПа режимов обтекания составило $182 \mathrm{BT} / \mathrm{cm}^{2}$ (при мощности анодного питания 70 кВт и угле атаки $30^{\circ}$, для датчика, расположенного на расстоянии 20 мм от нижнего края пластины).

\section{5. Определение тепловых потоков к низкокаталитической поверхности теплозащитной плитки орбитального корабля «Буран»}

Для низкотеплопроводного материала тепловой поток в установившемся режиме может быть определен из закона Стефана-Больцмана

$$
q_{w}=\varepsilon_{t} \sigma T_{w}^{4},
$$

где $q_{w}$ - плотность поверхностного теплового потока; $T_{w}$ - установившаяся температура поверхности (равновесная радиационная температура); $\varepsilon_{t}$ - интегральная степень черноты поверхности; $\sigma$ - постоянная Стефана-Больцмана.

На основе приведенного соотношения были определены тепловые потоки к поверхности теплозащитной плитки орбитального корабля «Буран» с черным низкокаталитическим покрытием.

Плитка имела размеры $150 \times 150$ мм и устанавливалась под углами атаки $0^{\circ}, 5^{\circ}$ и $10^{\circ}$ (рис. 13).

Для формирования потока плазмы применялось щелевое сопло с выходным сечением $80 \times 15$ мм.

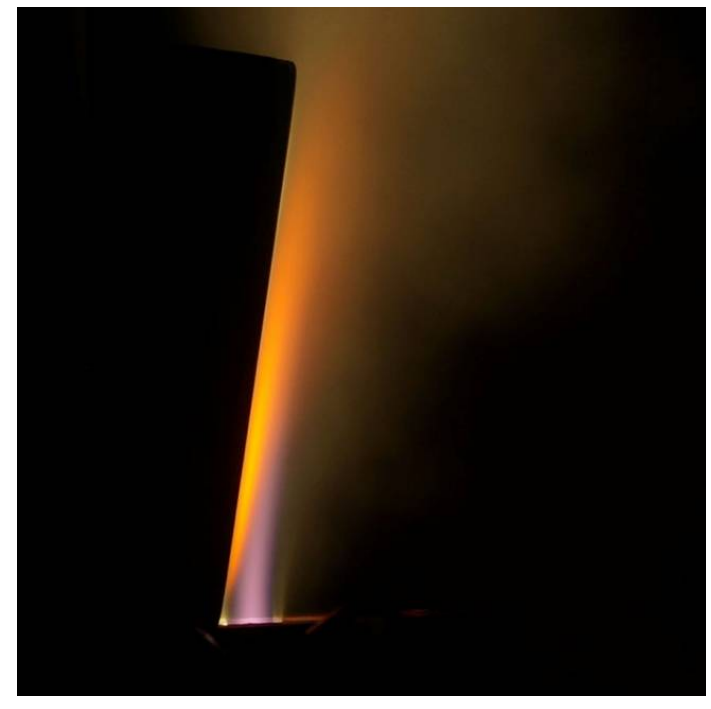

$a$

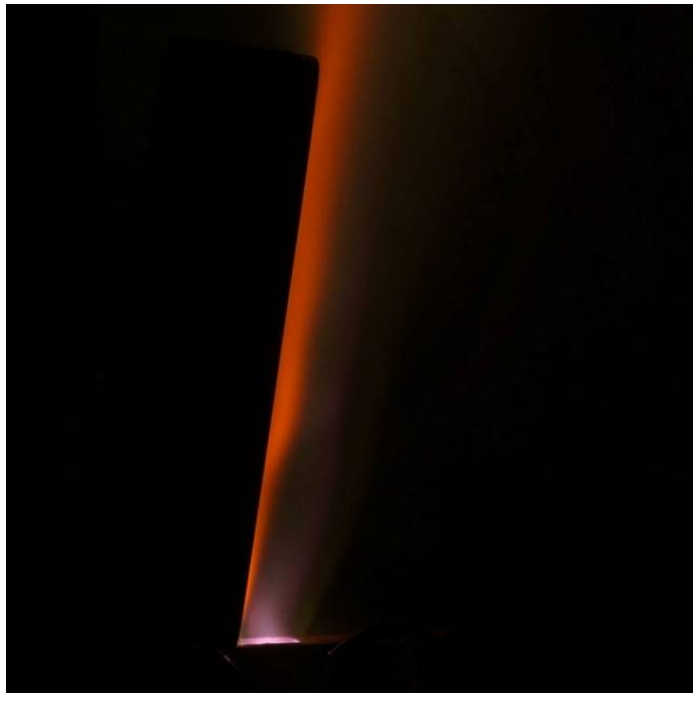

$\sigma$

Рис. 13. Теплозащитная плитка орбитального корабля «Буран» в дозвуковом $(a)$ и сверхзвуковом (б) потоке воздушной плазмы 
Пробные эксперименты в сверхзвуковом потоке плазмы показали существенно неравномерное распределение температур по поверхности плитки из-за ее взаимодействия со скачками уплотнения, поэтому все дальнейшие исследования велись при дозвуковых режимах обтекания.

Эксперименты проводились при давлении в камере установки 50 и 100 гПа для диапазона мощностей ВЧ-генератора плазмотрона по анодному питанию $20 \div 30$ кВт.

Поле температур поверхности регистрировалось термовизором «Тандем VS-415U». Термовизор требует предварительной установки спектральной степени черноты поверхности на длине волны 0.9 мкм. Для расчета тепловых потоков по формуле 3 необходимо знать интегральную степень черноты материала. На основе данных [19] спектральная степень черноты поверхности плитки была принята $\varepsilon_{\lambda}=0.87$, интегральная степень черноты принималась $\varepsilon_{t}=0.89$.

Примеры распределения температур по поверхности плитки в ходе эксперимента приведены на рис. 14. Вертикальная черная линия на рис. 14, $a$ и 14, б обозначает ось симметрии плитки и сопла.

Отмечено систематическое смещение струи плазмы относительно оси симметрии сопла, вызванное, вероятно, совместным влиянием закрутки потока в разрядном канале и некоторой асимметрии потока плазмы, вызванной конструктивной особенностью пятивиткогового индуктора (несимметричность токоподвода к спиральной катушке индуктора приводит к неоднородному распределению азимутальной компоненты магнитного поля).

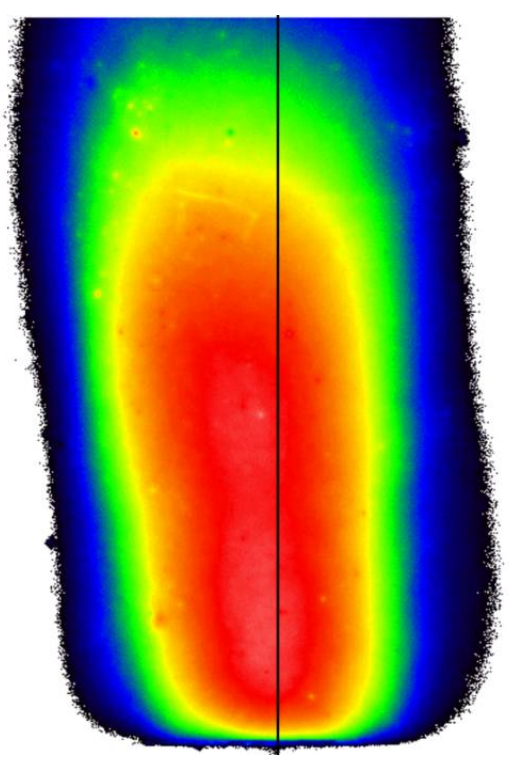

$a$

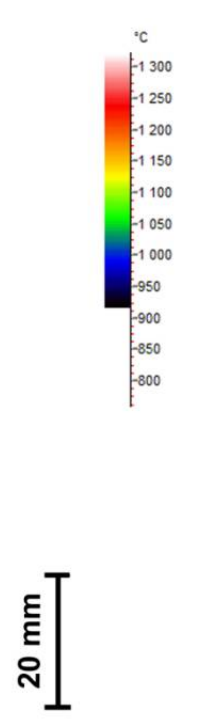

Рис. 14. Распределение температур по поверхности теплозащитной плитки, установленной под углом атаки $5^{\circ}$ при давлении в барокамере 100 гПа $(a)$ и 50 гПа (б), мощность плазмотрона по анодному питанию $N=30$ кВт, черная вертикальная линия соответствует оси симметрии плитки и сопла

Полученные графики распределения тепловых потоков вдоль вертикальной оси симметрии плитки для различных режимов испытаний приведены на рис. 15-20.

Как видно из термоизображений на рис. 14 и графиков распределения тепловых потоков на рис. 15-20, при давлении в барокамере 50 гПа пятно нагрева наиболее однородно и обеспечивает достаточно равномерное распределение температуры в области взаимодействия потока с поверхностью плитки. 


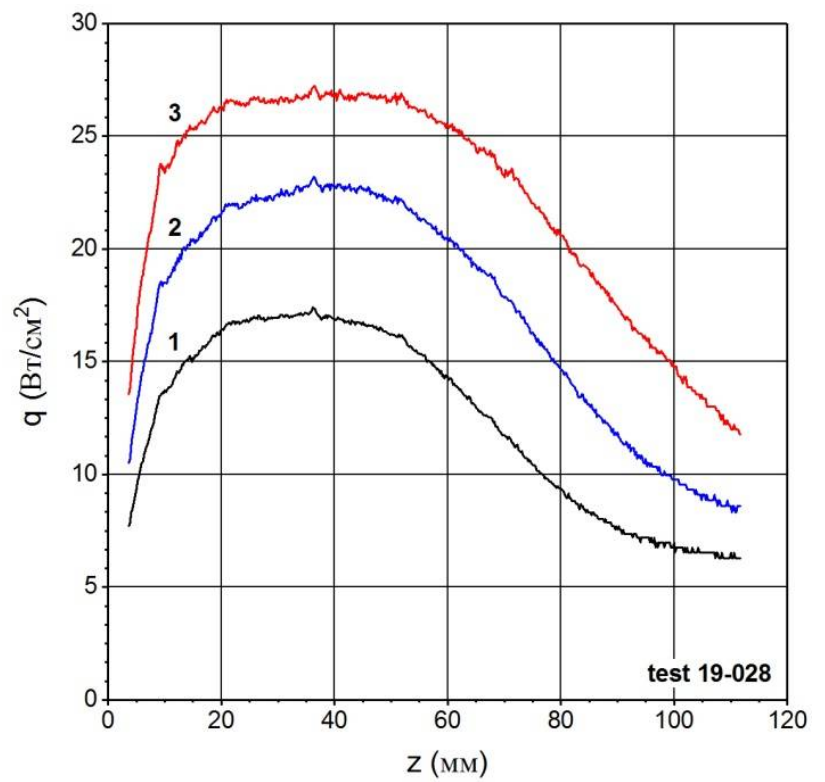

Рис. 15. Изменение теплового потока вдоль оси симметрии теплозащитной плитки для различных значений мощности плазмотрона при давлении в барокамере 100 гПа и угле атаки 0 градусов. z (мм) координата, отсчитываемая по поверхности плитки

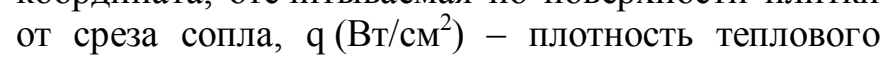
потока. Мощность плазмотрона по анодному питанию N: 1 (черный) - 20 кВт, 2 (синий) - 25 кВт, 3 (красный) - 30 кВт

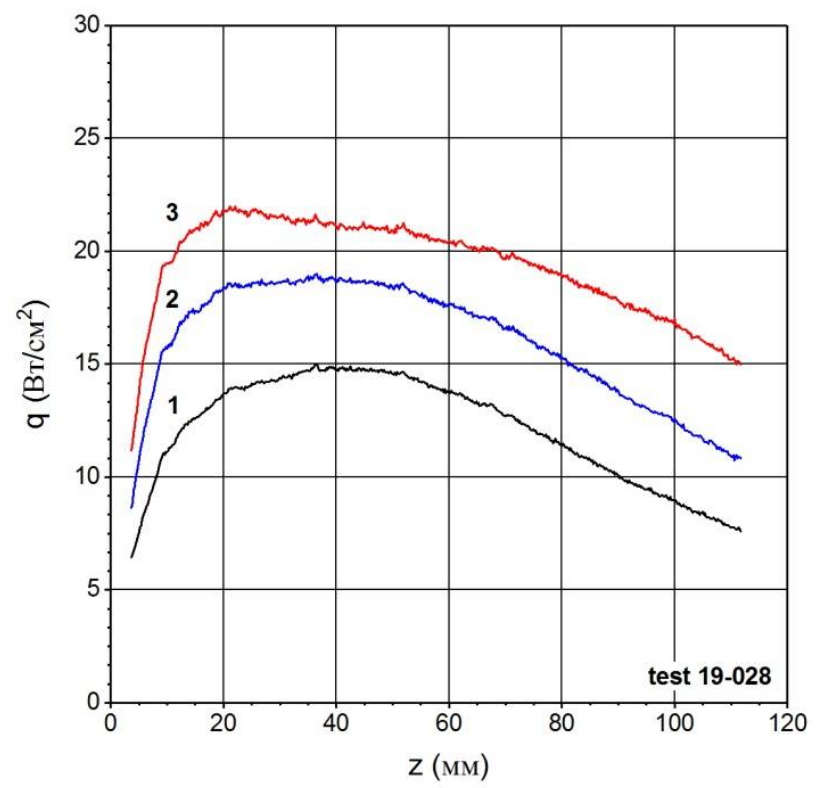

Рис. 16. Изменение теплового потока вдоль оси симметрии теплозащитной плитки для различных значений мощности плазмотрона при давлении в барокамере 50 гПа и угле атаки 0 градусов. z (мм) координата, отсчитываемая по поверхности плитки от среза сопла, $\mathrm{q}\left(\mathrm{BT} / \mathrm{cm}^{2}\right)$ - плотность теплового потока. Мощность плазмотрона по анодному питанию N: 1 (черный) - 20 кВт, 2 (синий) - 25 кВт, 3 (красный) -30 кВт 


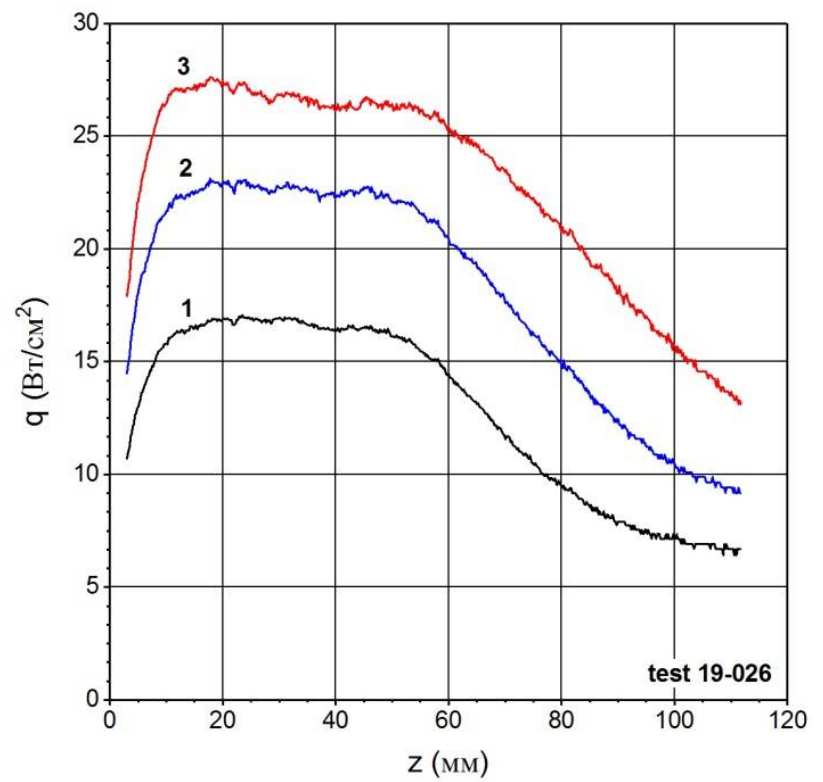

Рис. 17. Изменение теплового потока вдоль оси симметрии теплозащитной плитки для различных значений мощности плазмотрона при давлении в барокамере 100 гПа и угле атаки 5 градусов. z (мм) координата, отсчитываемая по поверхности плитки от среза сопла, $\mathrm{q}\left(\mathrm{BT} / \mathrm{cm}^{2}\right)$ - плотность теплового потока. Мощность плазмотрона по анодному питанию N: 1 (черный) - 20 кВт, 2 (синий) - 25 кВт, 3 (красный) -30 кВт

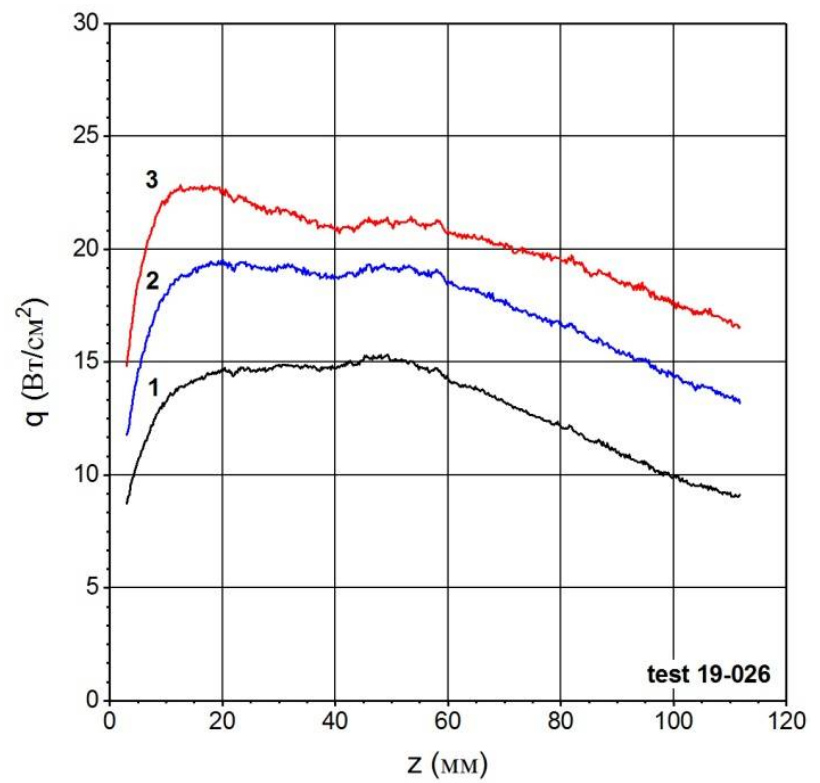

Рис. 18. Изменение теплового потока вдоль оси симметрии теплозащитной плитки для различных значений мощности плазмотрона при давлении в барокамере 50 гПа и угле атаки 5 градусов. z (мм) координата, отсчитываемая по поверхности плитки от среза сопла, q $\left(\mathrm{BT} / \mathrm{cm}^{2}\right)$ - плотность теплового потока. Мощность плазмотрона по анодному питанию N: 1 (черный) - 20 кВт, 2 (синий) - 25 кВт, 3 (красный) - 30 кВт 


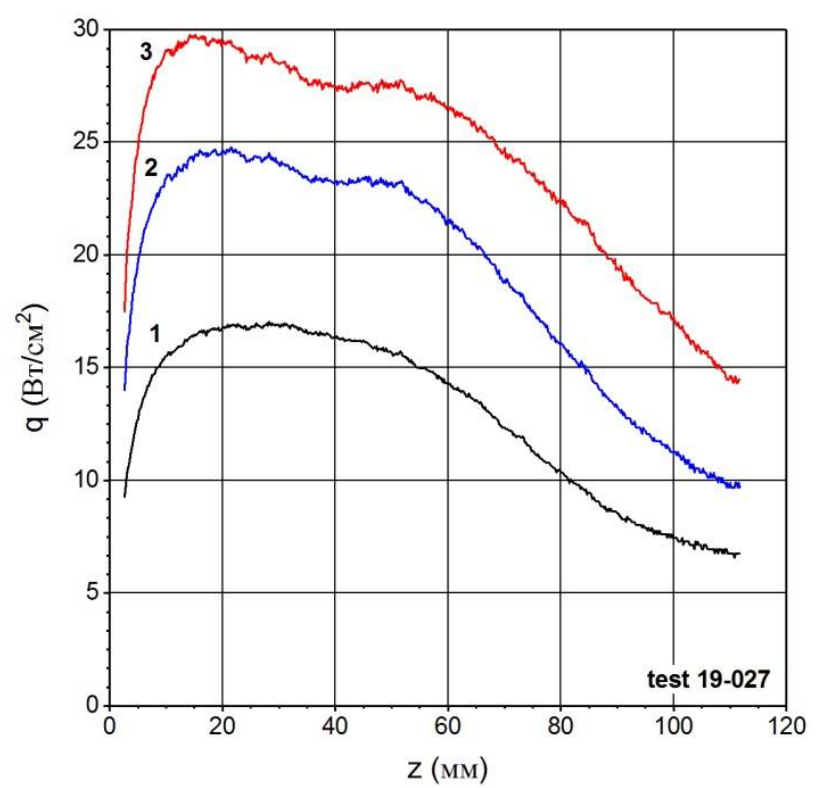

Рис. 19. Изменение теплового потока вдоль оси симметрии теплозащитной плитки для различных значений мощности плазмотрона при давлении в барокамере 100 гПа и угле атаки 10 градусов. z (мм) - координата, отсчитываемая по поверхности плитки от среза сопла, $\mathrm{q}\left(\mathrm{BT} / \mathrm{cm}^{2}\right)$ - плотность теплового потока. Мощность плазмотрона по анодному питанию N: 1 (черный) - 20 кВт, 2 (синий) - 25 кВт, 3 (красный) -30 кВт

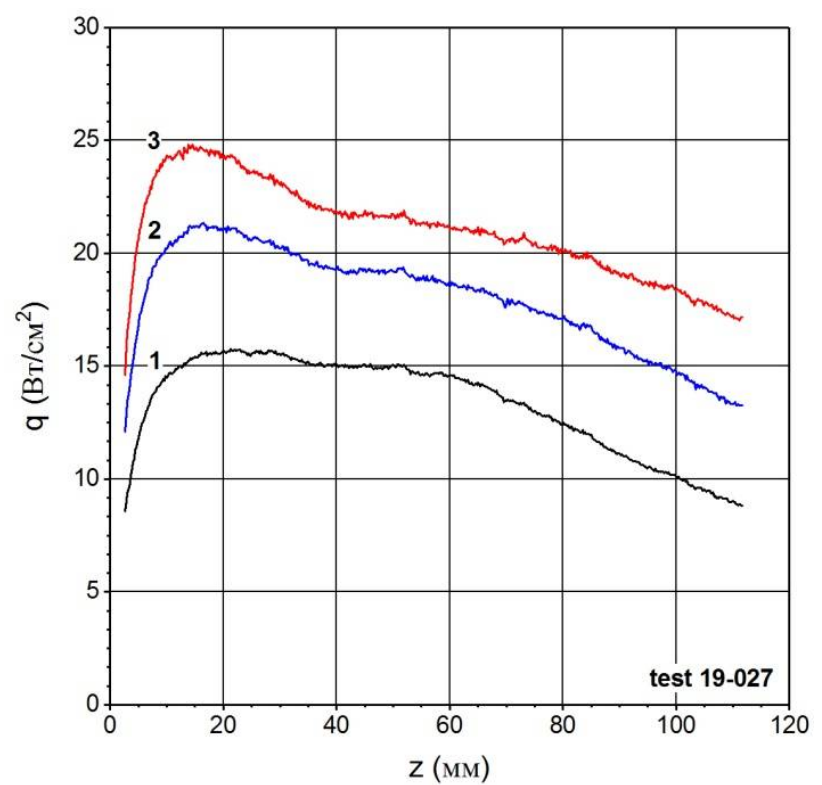

Рис. 20. Изменение теплового потока вдоль оси симметрии теплозащитной плитки для различных значений мощности плазмотрона при давлении в барокамере 50 гПа и угле атаки 10 градусов. z (мм) координата, отсчитываемая по поверхности плитки от среза сопла, $\mathrm{q}\left(\mathrm{BT} / \mathrm{cm}^{2}\right)$ - плотность теплового потока. Мощность плазмотрона по анодному питанию N: 1 (черный) - 20 кВт, 2 (синий) - 25 кВт, 3 (красный) - 30 кВТ 
На участке плитки, расположенном на расстоянии $40 \div 60$ мм от среза сопла, тепловой поток вдоль оси симметрии при давлении 50 гПа практически постоянен, что согласуется с измерениями, сделанными для медной модели.

На рис. 21 приведено пространственное представление распределения теплового потока по поверхности плитки при давлении 50 гПа, угле атаки $10^{\circ}$ и мощности 30 кВт, из которого видно, что ширина участка интенсивного нагрева составляет порядка 40 мм.

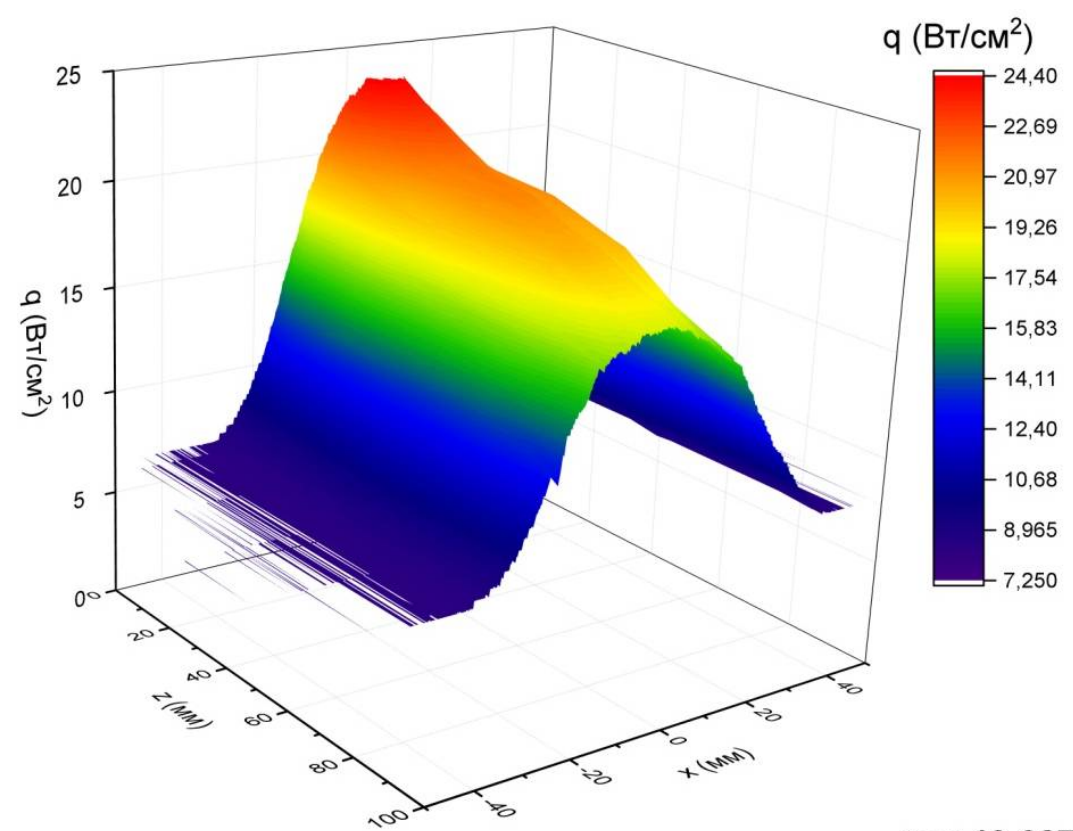

test 19-027

Рис. 21. Распределение теплового потока по поверхности плитки при давлении 50 гПа, угле атаки $10^{\circ}$ и мощности 30 кВт

В табл. 2 дается сравнение полученных тепловых потоков к поверхности плитки с низкокаталитическим покрытием и результатов измерений для медной пластины в точке, расположенной на расстоянии от среза сопла $z=40$ мм, на вертикальной оси симметрии. В обоих случаях угол атаки составлял $5^{\circ}$.

\section{Таблица 2}

\section{Тепловые потоки к поверхности пластины} под углом атаки $5^{\circ}(z=40$ мм, $p=50$ гПа)

\begin{tabular}{|c|c|c|}
\hline \multirow{2}{*}{$N$, кВт } & \multicolumn{2}{|c|}{ Тепловой поток $q, \mathrm{Bт} / \mathrm{cm}^{2}$} \\
\cline { 2 - 3 } & Медь & Плитка «Буран» \\
\hline 20 & 35.1 & 14.7 \\
\hline 25 & 49.5 & 18.8 \\
\hline 30 & 58.2 & 20.9 \\
\hline
\end{tabular}

Тепловые потоки к поверхности теплозащитной плитки орбитального корабля «Буран» в $2.4 \div 2.8$ раза ниже зарегистрированных на медной поверхности для того же режима обтекания. Учитывая, что поверхность материала теплозащитной плитки является низкокаталитической [20], а медная поверхность - высококаталитической, табл. 2 дает представление о возможном интервале реализуемых тепловых потоков в зависимости от каталитических свойств материала испытываемой пластины. 
В табл. 3 приведены значения тепловых потоков к поверхности теплозащитной плитки на расстоянии $z=40$ мм от нижнего края в зависимости от давления и угла атаки. Для постоянного угла атаки отмечается рост теплового потока с ростом давления в барокамере установки. Изменение угла атаки в интервале от $0^{\circ}$ до $10^{\circ}$ не оказывает заметного влияния на величину теплового потока.

\section{Таблиияа 3}

Тепловые потоки к поверхности пластины на расстоянии $z=40$ мм от нижнего края в зависимости от давления в камере установки и угла атаки

\begin{tabular}{|c|c|c|c|c|c|c|}
\hline \multirow{2}{*}{$N$, кВт } & \multicolumn{5}{|c|}{ Тепловой поток $q, \mathrm{BT} / \mathrm{cm}^{2}$} \\
\cline { 2 - 7 } & $\begin{array}{c}\alpha=0^{\circ}, \\
p=50 \text { гПа }\end{array}$ & $\begin{array}{c}\alpha=0^{\circ}, \\
p=100 \text { гПа }\end{array}$ & $\begin{array}{c}\alpha=5^{\circ}, \\
p=50 \text { гПа }\end{array}$ & $\begin{array}{c}\alpha=5^{\circ}, \\
p=100 \text { гПа }\end{array}$ & $\begin{array}{c}\alpha=10^{\circ}, \\
p=50 \text { гПа }\end{array}$ & $\begin{array}{c}\alpha=10^{\circ}, \\
p=100 \text { гПа }\end{array}$ \\
\hline 20 & 14.7 & 16.9 & 14.7 & 16.4 & 15.1 & 16.3 \\
\hline 25 & 18.6 & 22.8 & 18.8 & 22.3 & 19.3 & 23.2 \\
\hline 30 & 21.1 & 26.7 & 20.9 & 26.1 & 21.9 & 27.5 \\
\hline
\end{tabular}

\section{6. Заключение}

Использование щелевого сопла для испытания образцов в форме пластины под углом атаки существенно расширяет возможности установки ВГУ-4 по экспериментальному исследованию высокотемпературных материалов.

Для щелевого сопла с размерами выходного сечения $80 \times 15$ мм определен предпочтительный рабочий диапазон давлений в барокамере установки от 50 до 100 гПа.

C помощью нестационарных калориметрических датчиков определены тепловые потоки к высококаталитической поверхности медной пластины под углом атаки, обтекаемой диссоциированным воздухом при давлении 50 и 100 гПа. Максимальный зарегистрированный тепловой поток при давлении 50 гПа и угле атаки $30^{\circ}$ составил $182 \mathrm{BT} / \mathrm{cm}^{2}$ (при мощности анодного питания 70 кВт).

На участке поверхности медной пластины, расположенном в $40-60$ мм от ее нижнего края, при давлении в камере установки 50 гПа могут быть реализованы тепловые потоки к высококаталитической медной поверхности от $30 \mathrm{BT} / \mathrm{cm}^{2}$ (при мощности анодного питания 20 кВт и угле атаки $0^{\circ}$ ) до $140 \mathrm{BT} / \mathrm{cm}^{2}$ (при мощности анодного питания 70 кВт и угле атаки $\left.30^{\circ}\right)$.

Экспериментально определены параметры теплообмена низкокаталитической поверхности теплозащитной плитки орбитального корабля «Буран»под углами атаки $0^{\circ}, 5^{\circ}$ и $10^{\circ} \mathrm{c}$ диссоциированным потоком воздуха при давлении 50 и 100 гПа. Тепловые потоки к поверхности теплозащитной плитки в $2.4 \div 2.8$ раза ниже зарегистрированных на медной поверхности для того же режима обтекания.

Полученные результаты позволяют подобрать режимы для испытания образцов высокотемпературных материалов в форме пластины в зависимости от необходимых уровней тепловых потоков.

\section{Благодарности и ссылки на гранты}

Работа выполнена в рамках государственного задания АААА-А17-117021310383-2.

\section{Литература}

1. Vasil'evskii S.A., Gordeev A.N., Kolesnikov A.F. Local modeling of the aerodynamic heating of the blunt body surface in subsonic high-enthalpy air flow. Theory and experiment on a high-frequency plasmatron //Fluid Dynamics. - 2017. - Vol.52. - № 1. - Pp. 158-164. https://doi.org/10.1134/S001546281701015X 
2. Власов В.И., Залогин Г.Н., Ковалев Р.В., Рудин Н.Ф., Тренев М.Г. Условия моделирования теплообмена спускаемых аппаратов при скоростях входа $V=10 \div 11$ км/с в плазменных струях ВЧплазмотрона//Физико-химическая кинетика в газовой динамике. 2011. T.12. http://chemphys.edu.ru/issues/2011-12/articles/348/

3. Chazot O., Krassilchikoff H. W., Thoemel J. TPS ground testing in plasma wind tunnel for catalytic properties determination //46th AIAA aerospace sciences meeting and exhibit. - 2008. - P. 1252.

4. Owens W.P., Uhl J., Dougherty M., Lutz A., Meyers J., Fletcher D.G. Development of a 30kw inductively coupled plasma torch for aerospace material testing //10th AIAA/ASME Joint Thermophysics and Heat Transfer Conference. - 2010. - P. 4322. https://doi.org/10.2514/6.2010-4322

5. Muylaert J.M., Cipollini F., Auweter-Kurtz M., Balat M., Borrelli S., Conte D., Traineau J.C., Guelhan A., Enzian A. European plasma working group: status of activities and future plans //Hot Structures and Thermal Protection Systems for Space Vehicles. - 2003. - Vol. 521. - P. 321.

6. Kolesnikov A.F. The concept of local simulation for stagnation point heat transfer in hypersonic flowsApplications and validation //21st Aerodynamic Measurement Technology and Ground Testing Conference. - 2000. - P. 2515. https://doi.org/10.2514/6.2000-2515

7. Bityurin V.A., Bocharov A.N, Zalogin G.N., Knotko V.B., Krasilnikov A.V., Lineberry J.T. On MHD phenomena modeling at high frequency plasmatron //33rd Plasmadynamics and Lasers Conference. 2002. - P. 2253. https://doi.org/10.2514/6.2002-2253

8. Panerai F., Chazot O., Thoemel J. Plasma wind tunnel testing as support to the design of gas-surface interaction in-flight experiments //17th AIAA International Space Planes and Hypersonic Systems and Technologies Conference. - 2011. - P. 2276. https://doi.org/10.2514/6.2011-2276

9. Terrazas-Salinas I., Cornelison C. Test Planning Guide for NASA Ames Research Center Arc Jet Complex and Range Complex //Space Technology Division, NASA Ames Research Center, Moffett Field, CA. - 2009. - V. 94035.

10. Gokcen T., Skokova K., Alunni A. Computational Simulations of Panel Test Facility Flow: Compression-Pad Arc-Jet Tests //42nd AIAA Thermophysics Conference. - 2011. - P. 3635. https://doi.org/10.2514/6.2011-3635

11. Гордеев А.Н., Колесников А.Ф. Высокочастотные индукционные плазмотроны серии ВГУ //Сб. Актуальные проблемы механики: Физико-химическая механика жидкостей и газов. Москва, Наука. - 2010. - С. 151-177.

12. Гордеев А.Н., Колесников А.Ф. Новые режимы течения и теплообмена плазмы в высокочастотном индукционном плазмотроне ВГУ-4 //Физико-химическая кинетика в газовой динамике. 2008. - № 7. - C. 18. http://chemphys.edu.ru/issues/2008-7/articles/453/

13. Viladegut A., Chazot O. OFF-Stagnation point testing in plasma facility //Progress in Flight PhysicsVolume 7. - 2015. - Pp. 113-122. https://doi.org/10.1051/eucass/201507113

14. Gokcen T., Hui F., Taunk J., Noyes E., Schickele D. Calibration of the Truncated Panel Test Arc-Jet Facility //41st AIAA Thermophysics Conference. - 2009. - P. 4090. https://doi.org/10.2514/6.2009$\underline{4090}$

15. ASTM E457-08(2015), Standard Test Method for Measuring Heat-Transfer Rate Using a Thermal Capacitance (Slug) Calorimeter, ASTM International, West Conshohocken, PA, 2015, www.astm.org

16. Anderson L. A. Effect of surface catalytic activity on stagnation heat-transfer rates //AIAA Journal. 1973. - V. 11. - № 5. - Pp. 649-656. https://doi.org/10.2514/3.6806

17. Uhl J., Owens W., Dougherty M., Lutz A., Meyers J., Fletcher D. Pyrolysis simulation in an icp torch facility //42nd AIAA Thermophysics Conference. - 2011. - P. 3618. https://doi.org/10.2514/6.2011$\underline{3618}$

18. Брылкин Ю.В, Власов В. И., Залогин Г.Н., Кусов А.Л., Рудин Н.Ф. Экспериментальные исследования влияния структуры поверхности материалов на их каталитическую активность // Физико-химическая кинетика в газовой динамике. - 2015. - T. 16. - № 3 . http://chemphys.edu.ru/issues/2015-16-3/articles/600/ 
19. Дождиков В.С., Петров В.А. Излучательные характеристики теплозащитных материалов орбитального корабля «Буран» // Инж.-физ.ж. 2000. Т. 73. № 1. С. 26-30.

20. Баронец П.Н., Гордеев А.Н., Колесников А.Ф., Мысова В.М., Першин И.С., Прилепский В.Н., Рулев Ю.К., Труханов А.С., Якушин М.И. Отработка теплозащитных материалов орбитального корабля «БУРАН» на индукционных плазмотронах //Гагаринские научные чтения по космонавтике и авиации. $-1990 .-$ Т. 1991. - С. 41-52.

Статья поступила в редакцию 25 марта 2019 г. 